\title{
Antimicrobial Drug Therapy Problems Among Patients in the Outpatient Department of Ataye Hospital, Northeast Ethiopia
}

\section{Haile Kassahun (D) \\ Tefera Ayfokru}

Department of Pharmacy, College of Medicine and Health Sciences, Wollo University, Dessie, Ethiopia
Correspondence: Haile Kassahun Department of Pharmacy, College of Medicine and Health Sciences, Wollo University, Dessie, Ethiopia Email haile.kassahun@wu.edu.et
This article was published in the following Dove Press journal: Infection and Drug Resistance

Background: Antimicrobial drug therapy problems refer to incorrect and inappropriate utilization of antimicrobials which affect patient's health outcomes and results in bacterial resistance. Incorrect use of antimicrobial agents is a key driver for the spread of antimicrobial drug resistance. Improving drug therapy problems has an important effect on the patients' health, treatment costs, and enhancing patients' quality of life. Hence, the aim of the present study was to assess antimicrobial drug therapy problems among patients in the Outpatient Department of Ataye hospital, Northeast Ethiopia.

Methods: A hospital-based retrospective cross-sectional study design was used to assess antimicrobial drug therapy problems among patients in Ataye hospital from September 2018 to February 2019. Data were collected by trained graduating pharmacy students by reviewing medical records of patients using checklists and questionnaires.

Results: A total of 248 patient cards were included in this study. At least one antimicrobial drug therapy problem had occurred among 96 (38.7\%) of the study participants. The most common drug therapy problem was the need for additional drug therapy which was incurred by $38(15.3 \%)$ of the study participants and ineffective antimicrobial therapy was experienced by $22(8.9 \%)$ of the patients. Tetracyclines 25 (26\%), fluoroquinolones 19 (19.8\%), and penicillins $18(18.8 \%)$ were the most common classes of antimicrobials prone to drug therapy problems.

Conclusion: The current study revealed that nearly two-fifths of the study participants had experienced at least one form of antimicrobial drug therapy problem. The most common drug therapy problem was the need for additional drug therapy and the use of ineffective antimicrobial therapy. Tetracyclines, fluoroquinolones, and penicillins were the main classes of antimicrobials involved in the drug therapy problem.

Keywords: antimicrobial drug therapy problems, antimicrobials, Ataye hospital, Ethiopia

\section{Background}

Antimicrobials are among the drugs most commonly used in health-care systems. ${ }^{1}$ Incorrect use and abuse of antimicrobial agents are key drivers for the spread of antimicrobial drug resistance. ${ }^{2-5}$ Frequent and prolonged use of broad-spectrum antimicrobial agents has been associated with the emergence of antimicrobial resistance. $^{6-8}$

Drug therapy problem (DTP) is any undesirable event experienced by a patient related to drug therapy, which interferes with achieving the desired goals of the pharmacological intervention. In the absence of appropriate intervention, medication 
problems have a considerable negative impact on the health of the patients. DTPs are usually classified as: unnecessary drug therapy, the need for additional drug therapy, ineffective drug therapy, too low dosage, too high dosage, adverse drug reaction (ADR), and non-compliance. ${ }^{9,10}$ Antimicrobial drug therapy problems refers to incorrect and inappropriate utilization of antimicrobials which affect patient health outcomes and even result in bacterial resistance. ${ }^{11}$ Literature reviews regarding DTPs indicated that a total of 199 DTPs were identified among patients receiving outpatient antimicrobial therapy in the USA. ${ }^{12}$ Moreover, a study in the surgery ward of Jimma University Medical Center, northwest Ethiopia, showed that of 300 participants, antibiotic use-related problems were found in $69.3 \%$ of the study participants. Too low a dose was the top-ranking antibiotic use-related problem $(32.9 \%)$, followed by a too-high dose(20.7\%). ${ }^{13}$

There are a number of consequences of drug-related problems, ie, hospitalizations, long-term care admissions, emergency department (ED) visits, additional costs, morbidity, and mortality. A review of the literature concerning DTPs found that $28 \%$ of all ED visits are medicationrelated, of which $70-90 \%$ are preventable. Studies that focus on drug-related hospitalization revealed that 5-10\% of all admissions are drug-related. ${ }^{14}$ In a study conducted in Singapore, DTPs were found to be one of the major reasons for admission, resulting in $71.9 \%$ of patient admissions. ${ }^{15}$ Similarly, an observational study conducted in hospitals in the Netherlands indicated that out of 13,000 unintended admissions, $714(5.6 \%)$ were most likely due to issues related to drug therapy. ${ }^{16}$ In the USA, DTPs were the 4 th6 th cause of death with total costs of \$130-177.4 billion. ${ }^{17}$

DTP can occur everywhere, inpatient or outpatient, in every ward where drug therapy is applied for prevention, diagnosis, or management of the disease. ${ }^{17}$ Identifying DTPs is a major task that can be performed by clinical pharmacists and other health-care providers. On the other hand, the educational intervention of patients by clinical pharmacists can improve patients' adherence to drug therapy. ${ }^{11,19}$ Hence, improving drug therapy has an important effect on the patients' health, treatment costs, and enhancing patients' quality of life. ${ }^{18}$

In developing countries, including Ethiopia, antimicrobials are used more frequently than any other drugs for both bacterial and non-bacterial infections. ${ }^{20}$ However, very limited studies were done on the prevalence of antimicrobial DTPs in developing countries. To our knowledge, no previous study was done on antimicrobial DTPs among outpatients in Northeast Ethiopia. Hence, this study was aimed to assess DTPs among patients in the outpatient department (OPD) of Ataye hospital, Northeast Ethiopia.

\section{Methods}

\section{Study Area and Period}

This study was conducted in the OPD of Ataye hospital, Northeast Ethiopia. Ataye town, located in the Amhara region, is $270 \mathrm{~km}$ from Addis Ababa, Ethiopia. The hospital is one of the new public hospitals found in the country. The hospital does not have a formal antimicrobial stewardship program and there are no specific guidelines on antimicrobial use. The hospital is providing several health services with 40 beds serving 1000 inpatient and 150,000 outpatient visits a year. This study was conducted from February to May 2019.

\section{Study Design}

A hospital-based retrospective cross-sectional study design was used to investigate antimicrobial DTPs in OPD of Ataye hospital, Northeast Ethiopia.

\section{Source Population}

All patient cards in OPD of Ataye hospital from September 2018 to February 2019.

\section{Study Population}

Patient cards in OPD of Ataye hospital from September 2018 to February 2019, selected systematically and which fulfilled the inclusion criteria.

\section{Inclusion/Exclusion Criteria Inclusion Criteria}

Patients who were on antimicrobial drug therapy or candidate for antimicrobial drug therapy.

\section{Exclusion Criteria}

Patients with incomplete medical records.

\section{Sample Size Determination and Sampling Technique}

Sample size was determined based on the assumption of $80.1 \%$ proportion in southwest Ethiopia ${ }^{21}$ and using the single population proportion formula $n=Z^{2} \times p(1-p) / d^{2}$, where $Z=1.96, p=0.81, d=0.05$. Therefore, the sample size $n$ will be $(1.96)^{2} \times 0.81 \times(1-0.81) / 0.05^{2}=236$, and $5 \%$ for nonrespondent, the sample size was 248 . 


\section{Sampling Procedure}

The study units were identified using a systematic sampling method by the patient's card order. The sampling interval $(\mathrm{K})$ is calculated by dividing the source population $(\mathrm{N}=15,000)$ by the sample size $(\mathrm{n}=248)$; hence, the sampling interval is 60 . The first patient card was selected by a lottery method and the remaining patient cards were obtained by adding the sampling interval successively until 248 patient cards were selected.

\section{Study Variables \\ Dependent Variable}

Antimicrobial drug therapy problems.

\section{Independent Variables}

Age, sex, residence, comorbid conditions, and polypharmacy.

\section{Ethical Consideration}

The study was ethically approved by the ethical review committee of the college of medicine and health sciences of Wollo University (protocol number, WU/Phar/273/11) and permission was obtained from Ataye hospital officials to conduct this study. Due to the retrospective nature of the study, the consent of the patient was waived by the committee and all patient-related data were kept confidential. This study was conducted in accordance with the ethical guidelines of the Declaration of Helsinki.

\section{Data Collection Techniques}

Data were collected by trained graduating pharmacy students by reviewing medical records of patients using a checklist and structured questionnaires. Sociodemographic characteristics, types of comorbidity, and treatment regimens were recorded by reviewing medical records of patients. The appropriateness of drug therapy was evaluated using Ethiopian Standard Treatment Guideline, 2014. ${ }^{22}$ A pilot study was done in $5 \%$ of the sample size to ensure the validity of the data collection instruments.

\section{Data Analysis}

The collected data were analyzed using Statistical Package for Social Science (SPSS) version 20 and the findings were presented in the form of frequency and percentages using tables.

\section{Results}

Socio-Demographic Characteristics of the Study Participants

A total of 248 patient cards were included in this study. As shown in Table 1, the majority of the patients were females and $32(20.4 \%)$ of them were breastfeeding mothers. The majority, 165 (66.53\%), were from rural areas. Most of the respondents, $215(86.7 \%)$ had one comorbidity. On the other hand, all patients had no allergy history. Most patients, 118 (47.6\%), were on a single antimicrobial regimen.

\section{Common Indications for Antimicrobial Use}

The most commonly reported diseases for antimicrobial use were acute febrile illness, 97 (39.11\%), respiratory infection, 44 (17.74\%), and urinary tract infection, 39 (15.73\%). The most frequently prescribed classes of antimicrobials were fluoroquinolones, $56(22.58 \%)$, and penicillins, 45 (18.14\%). Cephalosporins, 28 (11.29), and other antimicrobials, $21(8.46 \%)$, were the least prescribed drug classes in the study area (Table 2).

\section{The Incidence of Antimicrobial Use Problems}

At least one antimicrobial DTP occurred among 96 (38.7\%) of the study participants. The most common DTP observed in this study was the need for an

Table I Socio-Demographic Characteristics of Patients in OPD of Ataye Hospital, Northeast Ethiopia $(n=248)$

\begin{tabular}{|l|l|l|}
\hline Variables & Categories & $\mathbf{n}(\%)$ \\
\hline Sex & $\begin{array}{l}\text { Female } \\
\text { Male }\end{array}$ & $\begin{array}{l}157(63.3) \\
91(36.7)\end{array}$ \\
\hline Age & $\begin{array}{l}\text { I8-32 years } \\
33-46 \text { years } \\
47-60 \text { years } \\
\text { 6I-74 years }\end{array}$ & $\begin{array}{l}115(46.4) \\
81(32.7) \\
37(14.9) \\
15(6)\end{array}$ \\
\hline Residence & Rural & $165(66.53)$ \\
& Urban & $83(33.46)$ \\
\hline Number of drugs per patient & One & $118(47.6)$ \\
& Two & $\begin{array}{l}94(37.9) \\
36(14.5)\end{array}$ \\
\hline Three & $215(86.7)$ \\
& One & $33(13.3)$ \\
\hline
\end{tabular}


Table 2 Common Indications and Antimicrobial Classes Used in OPD of Ataye Hospital, September 2018 to February 2019

\begin{tabular}{|l|l|l|}
\hline Variables & $\begin{array}{l}\text { Frequency } \\
\text { (n) }\end{array}$ & $\begin{array}{l}\text { Percent } \\
\text { (\%) }\end{array}$ \\
\hline Diagnosis & & \\
Respiratory infection & 44 & 17.74 \\
Urinary tract infection & 39 & 15.73 \\
Acute febrile illness & 97 & 39.11 \\
Gl infection & 24 & 9.677 \\
Skin and soft tissue infection & 18 & 7.25 \\
Acute febrile illness and Gl & 13 & 5.24 \\
infection & & \\
UTI and Gl infection & 4 & 1.6 \\
UTI and acute febrile illness & 6 & 2.4 \\
Respiratory infection and GI & 3 & 1.21 \\
infection & & \\
\hline Classes of medications & & \\
\hline Fluoroquinolones & 56 & 18.14 \\
Penicillins & 45 & 13.7 \\
Tetracyclines and fluoroquinolones & 35 & 11.69 \\
Tetracyclines & 34 & 11.29 \\
Penicillins and Macrolides & 29 & \\
Cephalosporins & 28 & \\
Others & 21 & \\
\hline
\end{tabular}

additional drug therapy that was incurred by 38 (15.3\%) of the patients. The second most common DTP was the use of ineffective antimicrobial therapy which was experienced by $22(8.9 \%)$ of the patients. In addition, $12(4.8 \%)$, of the patients received a sub-therapeutic dose of their treatment regimens. Moreover, overdosage and unnecessary antimicrobial therapy accounted for a relatively low proportion of DTPs (Table 3 ). The common cause of the need for additional drug therapy, 38 $(39.5 \%)$, was due to untreated medical conditions; ineffective antimicrobials, 21 (22.5\%), were due to

Table 3 Types of Antimicrobial Use Problems Identified in the OPD of Ataye Hospital, September 2018 to February 2019

\begin{tabular}{|l|l|l|}
\hline Variables & $\begin{array}{l}\text { Frequency } \\
\text { (n) }\end{array}$ & $\begin{array}{l}\text { Percent } \\
\text { (\%) }\end{array}$ \\
\hline $\begin{array}{l}\text { The need for additional drug } \\
\text { therapy }\end{array}$ & 38 & 15.3 \\
Ineffective drug therapy & 22 & \\
Dosage too low & 12 & 8.9 \\
Dosage too high & 12 & 4.8 \\
Unnecessary drug therapy & 12 & 4.8 \\
ADR & - & 4.8 \\
\hline
\end{tabular}

antimicrobials being used that were not the most effective for the disease condition. Similarly, a too-high dose, $12(12.5 \%)$, was mostly due to a long duration on antimicrobial treatment; a too-low dose, $12(12.5 \%)$, was due to the dose being too low to produce the desired response, and unnecessary antimicrobial therapy was mainly due to no valid medical condition being obtained among $11(11.45 \%)$ of patients.

Analysis of drug classes involved in DTPs revealed that tetracyclines, 25 (26\%), were the most prevalent classes of drugs involved in the DTPs. The majority of DTPs also occurred in patients treated with fluoroquinolones, 19 (19.8\%), and penicillins, 18 (18.8\%). In contrast, the lowest percentage of DTPs occurred in patients treated with the combination of tetracyclines and fluoroquinolones regimens (Table 4).

\section{Discussion}

Antimicrobials were the most frequently prescribed classes of drugs. The proper use of antimicrobials will have a positive impact on reducing antimicrobial resistance development, morbidity and mortality, and improving the cost of health care. ${ }^{20}$ The risk of emerging antibacterial resistance due to overuse and underuse of antimicrobials has often been reported to be the most worrying aspect of antibiotic treatment. ${ }^{23}$ DTPs can result in negative patient outcomes and are associated with failure of treatment, hospital readmissions, ED visits, increased cost, increased morbidity, and increased risk of death. ${ }^{12,14,24}$

Clinicians may not be aware of the actual burden of DTPs. Identification and documentation of DTPs will help to design preventive strategies of drug-related therapy problems and provide responsible care for patients. To our knowledge, this is the first study to comprehensively characterize antimicrobial DTPs among patients in the OPD of

Table 4 Classes of Antimicrobials with Drug Therapy Problems in the OPD of Ataye Hospital, September 2018 to February 2019

\begin{tabular}{|l|l|}
\hline Antimicrobial Classes & $\begin{array}{l}\text { Drug Therapy Problems, } \\
\text { n (\%) }\end{array}$ \\
\hline Tetracyclines & $25(26)$ \\
Fluoroquinolones & $19(19.8)$ \\
Penicillins & $18(18.8)$ \\
Penicillins and macrolides & $10(10.4)$ \\
Cephalosporins & $9(9.4)$ \\
Tetracyclines and & $4(4.2)$ \\
fluoroquinolones & \\
Others & $11(11.5)$ \\
\hline
\end{tabular}


Ataye hospital, Northeast Ethiopia. Hence, the aim of the present study was to assess drug therapy problems related to antimicrobials among patients in the OPD of Ataye hospital, northeast Ethiopia.

The present study revealed that $38.7 \%$ of the study participants had at least one form of antimicrobial DTP during their hospital visit. This finding is comparable to a study done in Brazil $(33.6 \%)^{3}$ and lower than studies conducted in three hospitals of southwest Ethiopia $(80.1 \%){ }^{21}$ Tikur Anbessa specialized hospital, Ethiopia $(52 \%),{ }^{25}$ and USA (63.2\%). ${ }^{12}$ This might be due to differences in the study population, study design, study period, and study setting.

Antimicrobials were among the most commonly prescribed drugs in hospitals. In this study, fluoroquinolones $(22.58 \%)$, and penicillins (18.14\%) were the most frequently prescribed categories of antimicrobial drugs. This might be due to infectious diseases including acute febrile illness and minor respiratory and urinary tract infections being managed empirically with broad-spectrum penicillins and fluoroquinolones in the study area.

The present study indicated that the most frequent type of antimicrobial DTP observed in this study was the need for additional drug therapy, $38(15.3 \%)$. In contrast to this finding, the need for additional drug therapy accounted for a larger proportion of antimicrobial DTPs in medical wards of Jimma University hospital, Ethiopia (29.6\%), and three hospitals of southwest Ethiopia. ${ }^{21}$ This might be due to differences in study design and health-care settings of the study area.

According to this study, ineffective antimicrobial drug therapy was incurred by $22(8.9 \%)$ of the patients. This finding is comparable to a study done in medical wards of Jimma University hospital, Ethiopia, ${ }^{6}$ and lower than a study conducted in the surgical ward of Jimma University medical Center, Ethiopia. ${ }^{13}$ This lower percentage of ineffective antimicrobial therapy might be due to the use of broad-spectrum antimicrobial combinations in the study area.

In this study, the prevalence of too low a dose of antimicrobials is $4.8 \%$, which is lower than a study done in the medical wards of Jimma University hospital, Ethiopia $(28.9 \%)^{6}$ The use of too low-dose antimicrobials might contribute to the development of antimicrobial resistance. Too high-dose and unnecessary antimicrobial therapy were also observed among $4.8 \%$ of patients. The use of high dose antimicrobials might result in dose-dependent toxicities of antimicrobial drugs.
According to the present study, fluoroquinolones, $19.8 \%$, were the second most common class of antimicrobials involved in the DTPs. This finding is lower than the study conducted in Metro medical center in Cleveland, ${ }^{26}$ where $39 \%$ of fluoroquinolones have DTPs. This variation might be due to the limited usage of fluoroquinolones in the study area.

\section{Conclusion}

The current study revealed that nearly two-fifths of the study participants had experienced at least one form of antimicrobial DTPs. The most common antimicrobial DTPs were the need for additional drug therapy and the use of ineffective antimicrobial drug therapy. Tetracyclines, fluoroquinolones, and penicillins were the main classes of antimicrobials involved in the DTPs. Hence, the involvement of interdisciplinary health-care professionals is required to minimize antimicrobial DTPs in the study area.

\section{Abbreviations}

ADR, adverse drug reaction; DTP, drug therapy problem; DTPs, drug therapy problems; ED, emergency department; OPD, Outpatient Department; SPSS, Statistical Package for Social Science; USA, United States of America.

\section{Data Sharing Statement}

All data are presented within the article.

\section{Acknowledgments}

The author acknowledges administrative staff in Ataye hospital for facilitating the data collection process.

\section{Funding}

There is no funding to report.

\section{Disclosure}

The authors report no conflicts of interest in this work.

\section{References}

1. Kiivet R-A, Dahl M-L, Llerena A, Maimets M, Wettermark B, Berecz R. Antibiotic use in 3 European university hospitals. Scand J Infect Dis. 1998;30(3):277-280. doi:10.1080/00365 549850160936

2. Staff PO. Correction: prescribing patterns and associated factors of antibiotic prescription in primary health care facilities of Kumbo East and Kumbo West Health Districts, North West Cameroon. PLoS One. 2018;13(4): $\mathrm{e} 0196861$.

3. Tong S, Pan J, Lu S, Tang J. Patient compliance with antimicrobial drugs: a Chinese survey. Am J Infect Control. 2018;46(4):e25-e9. doi:10.1016/j.ajic.2018.01.008 
4. Blix HS, Viktil KK, § R, et al. The majority of hospitalised patients have drug-related problems: results from a prospective study in general hospitals. Eur J Clin Pharmacol. 2004;60(9):651-658. doi:10. 1007/s00228-004-0830-4

5. Aslam A, Gajdács M, Zin CS, Binti Abd Rahman NS, Ahmed SI, Jamshed SQ. Public awareness and practices towards self-medication with antibiotics among the Malaysian population. A development of questionnaire and pilot-testing. Antibiotics. 2020;9(2):97. doi:10.3390/antibiotics9020097

6. Yadesa TM, Gudina EK, Angamo MT. Antimicrobial use-related problems and predictors among hospitalized medical in-patients in Southwest Ethiopia: prospective observational study. PLoS One. 2015;10(12):e0138385. doi:10.1371/journal.pone.0138385

7. Gajdács M, Bátori Z, Ábrók M, Lázár A, Burián K. Characterization of resistance in gram-negative urinary isolates using existing and novel indicators of clinical relevance: a 10-year data analysis. Life. 2020;10(2):16. doi:10.3390/life10020016

8. Gajdács M, Urbán E. Resistance trends and epidemiology of citrobacter-enterobacter-serratia in urinary tract infections of inpatients and outpatients (RECESUTI): a 10-year survey. Medicina. 2019;55(6):285. doi:10.3390/medicina55060285

9. Niriayo YL, Kumela K, Kassa TD, Angamo MT. Drug therapy problems and contributing factors in the management of heart failure patients in Jimma university specialized hospital, Southwest Ethiopia. PLoS One. 2018;13(10):e206120. doi:10.1371/journal.pone.0206 120

10. Degu A, Njogu P, Weru I, Karimi P. Assessment of drug therapy problems among patients with cervical cancer at Kenyatta National Hospital, Kenya. Gynecol Oncol Res Pract. 2017;4(1):15. doi:10.1186/s40661-017-0054-9

11. Peterson C, Gustafsson M. Characterisation of drug-related problems and associated factors at a clinical pharmacist service-naive Hospital in Northern Sweden. Drugs Real World Outcomes. 2017;4 (2):97-107. doi:10.1007/s40801-017-0108-7

12. Hale CM, Steele JM, Seabury RW, Miller CD. Characterization of drug-related problems occurring in patients receiving outpatient antimicrobial therapy. J Pharm Pract. 2017;30(6):600-605. doi:10.1177/ 0897190016688771

13. Tefera GM, Feyisa BB, Kebede TM. Antimicrobial use-related problems and their costs in surgery ward of Jimma university medical center: prospective observational study. PLoS One. 2019;14:5. doi:10.1371/journal.pone.0216770

14. Bizuneh GK, Adamu BA, Bizuayehu GT, Adane SD. A prospective observational study of drug therapy problems in pediatric ward of a referral hospital, Northeastern Ethiopia. Int $J$ Pediatr. 2020;2020:1-6. doi:10.1155/2020/4323189
15. Koh Y, Li SC, Fatimah M. Therapy related hospital admission in patients on polypharmacy in Singapore: a pilot study. Pharm World Sci. 2003;25(4):135-137. doi:10.1023/A:1024896328720

16. Leendertse AJ, Egberts AC, Stoker LJ, van den Bemt PM. Frequency of and risk factors for preventable medication-related hospital admissions in the Netherlands. Arch Intern Med. 2008;168(17):1890-1896. doi:10.1001/archinternmed.2008.3

17. Tefera GM, Zeleke AZ, Jima YM, Kebede TM. Drug therapy problems and the role of clinical pharmacist in surgery ward: prospective observational and interventional study. Drug Healthc Patient Saf. 2020;12:71. doi:10.2147/DHPS.S251200

18. Srikanth A. Assessment of drug related problems and its associated factors among medical ward patients in university of gondar teaching hospital, Northwest Ethiopia: a prospective cross-sectional study. J Basic Clin Pharm. 2017;8.

19. Garedow AW, Mulisa Bobasa E, Desalegn Wolide A, et al. Drugrelated problems and associated factors among patients admitted with chronic kidney disease at Jimma university medical center, Jimma zone, Jimma, Southwest Ethiopia: a hospital-based prospective observational study. Int J Nephrol. 2019;2019:1-9. doi:10.1155/2019/ 1504371

20. Mama M, Mamo A, Usman H, Hussen B, Hussen A, Morka G. Inappropriate antibiotic use among inpatients attending Madda Walabu University Goba Referral Hospital, Southeast Ethiopia: implication for future use. Infect Drug Resist. 2020;13:1403-1409. doi:10.2147/IDR.S251151

21. Yadesa T. Inappropriate use of antimicrobials and the determinants among patients hospitalized in 3 hospitals (Mizan, Bonga and Tepi) in Southwest Ethiopia. $J$ Bioanal Biomed. 2017;9:073-079. doi:10.4172/1948-593X.1000157

22. Food, Medicine and Health Care Administration and Control Authority of Ethiopia. Standard Treatment Guidelines for General Hospitals. 3rd ed. 2014.

23. Blix HS, Viktil KK, Moger TA, Reikvam A. Risk of drug-related problems for various antibiotics in hospital: assessment by use of a novel method. Pharmacoepidemiol Drug Saf. 2008;17(8):834-841. doi:10.1002/pds. 1595

24. Birarra MK, Heye TB, Shibeshi W. Assessment of drug-related problems in pediatric ward of Zewditu memorial referral hospital, Addis Ababa, Ethiopia. Int J Clin Pharm. 2017;39(5):1039-1046. doi:10.1007/s11096-017-0504-9

25. Ayalew MB, Megersa TN, Mengistu YT. Drug-related problems in medical wards of Tikur Anbessa specialized hospital, Ethiopia. J Res Pharm Pract. 2015;4(4):216. doi:10.4103/2279-042X.167048

26. Werner NL, Hecker MT, Sethi AK, Donskey CJ. Unnecessary use of fluoroquinolone antibiotics in hospitalized patients. BMC Infect Dis. 2011;11(1):187. doi:10.1186/1471-2334-11-187
Infection and Drug Resistance

\section{Publish your work in this journal}

Infection and Drug Resistance is an international, peer-reviewed openaccess journal that focuses on the optimal treatment of infection (bacterial, fungal and viral) and the development and institution of preventive strategies to minimize the development and spread of resistance. The journal is specifically concerned with the epidemiology of antibiotic resistance and the mechanisms of resistance development and diffusion in both hospitals and the community. The manuscript management system is completely online and includes a very quick and fair peerreview system, which is all easy to use. Visit http://www.dovepress.com/ testimonials.php to read real quotes from published authors. 